\title{
Desenvolvimento de uma Sequência Didática para orientar os técnicos na condução educativa das visitas escolares às estações de tratamento de esgoto
}

\author{
Development of a Didactic Sequence to guide technicians in the educational conduct of school visits \\ to sewage treatment plants
}

Elaboración de una Secuencia Didáctica para guiar a los técnicos en la conducción educativa de las visitas escolares a las plantas de tratamiento de aguas residuales

\section{Resumo}

O presente trabalho consiste no desenvolvimento de uma sequência didática (SD) para orientar os profissionais técnicos na condução das visitas às Estações de Tratamento de Efluentes (ETE). A sequência didática foi laborada como estratégia para lapidar a visita transformando o conhecimento técnico em ensinado, e seu desenvolvimento foi articulado com o conteúdo teórico ministrado em escolas públicas de níveis fundamental e médio. Para analisar o conteúdo de Química foram escolhidos dois livros utilizados nas escolas públicas da cidade de Itajubá-MG. Cada etapa do tratamento de esgoto representa um elemento na SD, que foi elaborada com base na teoria de transposição didática defendida por Chevallard (1991) e elaborada considerando-se os passos da SD defendido por Zabala (1998). A SD foi analisada segundo os princípios da Transposição Didática (TD) defendida por Astolfi (1995). Propôs-se ainda a utilização de um questionário a ser preenchido pelo visitante ao final da visita a fím de aperfeiçoar da SD. Espera-se com esta SD, auxiliar os profissionais técnicos durante a visita e prover um maior aproveitamento da mesma pelos estudantes de ensino básico.

Palavras-chave: Transposição Didática; Visitas escolares; Educação não-formal; Roteiro.

\begin{abstract}
The present work consists of the development of a didactic sequence (DS) to guide technical professionals in conducting visits to Wastewater Treatment Plants (WWTP). The didactic sequence was worked as a strategy to enhance the visit by transforming the technical knowledge into taught knowledge, and its development was articulated with the theoretical content taught in public elementary and high schools. To analyze the chemistry content, two books used in public schools in the city of Itajubá-MG were chosen. Each step of sewage treatment represents an element in the DS, which was elaborated based on the theory of didactic transposition advocated by Chevallard (1991) and elaborated considering the steps of the DS advocated by Zabala (1998). The DS was analyzed according to the principles of Didactic Transposition (DT) advocated by Astolfi (1995). It was also proposed the use of a questionnaire to be filled in by the visitor at the end of the visit in order to improve the DS. It is hoped that this DS will help the technical professionals during the visit and to provide a better use of the visit by students of basic education.
\end{abstract}

Keywords: Didactic Transposition; School visits; Non-formal education; Script.

\section{Resumen}

El presente trabajo consiste en el desarrollo de una secuencia didáctica (SD) para orientar a los profesionales técnicos en la conducción educativa de las visitas escolares a las Estaciones Depuradoras de Aguas Residuales (EDAR). La secuencia didáctica se trabajó como estrategia para lapidar la visita transformando el conocimiento técnico en conocimiento enseñado, y su desarrollo se articuló con los contenidos teóricos que se imparten en las escuelas 
públicas de los niveles primario y secundario. Para analizar el contenido de la química fueron elegidos dos libros utilizados en las escuelas públicas de la ciudad de Itajubá-MG. Cada etapa del tratamiento de las aguas residuales representa un elemento de la $\mathrm{SD}$, que fue elaborada a partir de la teoría de la transposición didáctica defendida por Chevallard (1991) y elaborada considerando las etapas de la SD defendidas por Zabala (1998). El DS fue analizado según los principios de la Transposición Didáctica (TD) defendidos por Astolfi (1995). También se propuso el uso de un cuestionario que el visitante debe rellenar al final de la visita para mejorar el SD. Se espera que esta SD ayude a los profesionales técnicos durante la visita y que permita un mejor aprovechamiento de la misma por parte de los estudiantes de educación básica.

Palabras clave: Transposición didáctica; Visitas escolares; Educación no formal; Guión.

\section{Introdução}

As visitas técnicas a empresas, vêm ganhando espaço como estratégia de ensino utilizada por professores, para contextualizar o conteúdo visto em sala de aula, com o cotidiano dos alunos. Na concepção de Costa et. al. (2019, p.1), a visita técnica apresenta-se como "grande aliada na construção do conhecimento, apresentando-se como uma peça-chave, permitindo que os alunos assimilem de forma didática os conteúdos trabalhados pelos professores com a realidade ambiental, social e histórica em que estes estão inseridos”.

As visitas técnicas, constituem uma gama de ações voltadas à educação em espaços não formais de ensino, ou seja, fazem parte daquela educação que vai além dos muros da escola, a educação não formal, na qual Lopes et. al. (2015, p. 7211) definem que, "as atividades acontecem em ambientes e situações interativas construídas coletivamente, sendo uma educação complementar, tendo a intencionalidade na ação no ato de participar, de aprender e de transmitir ou trocar saberes".

Pela própria natureza da sua atividade, a Companhia de Saneamento de Minas Gerais - COPASA sempre manteve um forte vínculo com as instituições de ensino e o público escolar. O estudo da água, do processo de tratamento, das noções básicas de higiene e limpeza, e das doenças de veiculação hídrica são assuntos ligados diretamente ao saneamento e fazem parte do currículo escolar das instituiçõos brasileiras de ensino básico. Atender as solicitações de visitas às instalações da COPASA e a ministração de palestras sempre foram atividades que fizeram e fazem parte da rotina da empresa, a qual desenvolveu um programa especialmente para prover essa aproximação (Copasa, 2020).

O Programa "Chuá” de Educação Sanitária e Ambiental, inicialmente denominado "Projeto Chuá", completou no ano de 2008, 16 anos de existência e a marca de mais de um milhão de alunos, apenas do $6^{\circ}$ ano do Ensino Fundamental, que visitaram as Estações de Tratamento de Água da COPASA. O programa foi desenvolvido com intuito de atender as solicitações de visita às instalações da COPASA, e ministração de palestras nas escolas, com o objetivo de aproximar a empresa da sociedade; e além destas atividades, o programa desenvolve concursos de redação, gincanas, feiras de desapego e feiras verdes.

Houve também a confecção de materiais, como a Revista Chuá, material desenvolvido inicialmente para alunos do sexto ano do ensino fundamental, mas que agora atende todo o público escolar. A revista foi desenvolvida a partir do sexto ano, devido a proposta pedagógica de ensino e por orientações da Superintendência Regional de Ensino de MG, as quais forneciam o suporte necessário ao programa; porém o programa Chuá, não apresenta práticas pedagógicas voltadas especificamente para as visitas às ETE, seja por falta de profissionais ou por falta de estrutura das unidades de tratamento de esgoto.

Na cidade de Itajubá, por exemplo, as visitas à ETE podem ser agendadas pelo site ou na agência de atendimento da COPASA. Para tal, são definidos alguns critérios, entre eles a idade mínima de 12 anos para os visitantes e a proibição da visita ao laboratório. De acordo com a estrutura da ETE, os visitantes devem ser divididos em pequenos grupos, respeitando o limite máximo de 10 pessoas; além disso, cada grupo deverá ter no mínimo 03 monitores que por sua vez, são de responsabilidade da escola. Antes da visita, os funcionários da ETE realizam o isolamento de algumas áreas com correntes plásticas, removem da unidade qualquer tipo de animal seja doméstico ou não, que por ventura estejam presentes no local. Os 
visitantes precisam estar com calçados fechados e sem salto alto por questões de segurança e não é permitido uso de pranchetas, mochilas, bem como fotografar ou filmar unidades da empresa.

Diferentemente, na ETE Arrudas localizada em Belo Horizonte, capital do estado de Minas Gerais, há um programa de auto monitoramento no qual o visitante entra em uma sala, onde através de um aquário visualiza que o esgoto tratado é lançado junto com espécies aquáticas presentes no efluente tratado; ou seja, ela conta com um sistema de bio-monitoramento das espécies de peixes da bacia hidrográfica do Rio das Velhas.

Devido ao conhecimento de várias unidades de tratamento de esgoto do Sul de Minas Gerais por meio de visitas, verificou-se que estas apresentam estrutura física que não permitem a utilização de vídeos e apresentações durante as visitas escolares; como exemplo, cita-se a ETE da cidade de Itajubá que não possui estrutura com sala de vídeos e acesso a laboratórios.

Como o programa Chuá não apresenta uma proposta específica para orientar a condução das visitas escolares a ETE, julga-se necessário desenvolver um roteiro para auxiliar os profissionais técnicos durante a explicação da visita aos estudantes de ensino básico. Neste sentido, o presente trabalho consiste na utilização de técnicas de transposição didática, a qual de acordo com Polidoro \& Stigar (2010, p. 2), "pode ser entendida como a passagem do saber científico ao saber ensinado" como base de a construção de uma sequência didática (SD) para orientar a equipe técnica da unidade de tratamento de esgoto na condução educativa das visitas escolares.

Para Costa et. a.l (2021, p. 14) em seu trabalho que engloba em sua temática o tratamento de água, destacam que com a introdução de temas correlatos em atividades didáticas se "possibilita que o professor auxilie os alunos na construção de valores essenciais para o mundo em que vivemos atualmente; valores estes como a consciência da importância da preservação da natureza e de seus recursos".

\section{Metodologia}

\subsection{Contexto da pesquisa}

A ETE utilizada como referência para a elaboração da sequência didática é a ETE da cidade de Itajubá, que recebe visitas de diversas instituições públicas e privadas de ensino, contribuindo desta forma como espaço não formal de ensino, pois além de realizar o tratamento dos efluentes domésticos gerados pela população, desempenha significante papel educacional.

Durante a visita à ETE Itajubá, os visitantes percorrem os processos do tratamento preliminar, que contém grades que separam os sólidos grosseiros do esgoto. Nas fases do tratamento preliminar, é visitada a caixa de areia, a calha Parshall e o medidor de vazão; posteriormente, os visitantes passam pela caixa de carvão ativado, e depois a próxima etapa, é o reator Upflow Anaerobic Sludge Blanket - UASB, que pela tradução é denominado Reator Anaeróbio de Manta de lodo ou de fluxo ascendente (Hamerski, 2012). Em seguida os visitantes seguem para a etapa de queima dos gases gerados no tratamento de esgoto, e a última etapa visitada, se denomina leito de secagem (COPASA, 2020).

Como supracitado, até a realização deste trabalho, a ETE Itajubá não contava com nenhum roteiro para orientar as visitas, sendo que durante elas, os técnicos vão relatando cada etapa do tratamento aos alunos, porém sem nenhum objetivo educacional. Sendo assim, os aspectos técnicos são predominantes em suas falas, o que se torna contraproducente do ponto de vista didático, visto que os alunos podem apresentar dificuldades na compreensão dos termos expostos, assim como na compreensão dos aspectos científicos-tecnológicos das etapas do processo de tratamento.

\subsection{Caracterização da Pesquisa}

O presente trabalho utiliza-se de análise qualitativa, pois o interesse maior está na análise de seu processo e não de seu resultado; além disso, tentamos compreender a totalidade do fenômeno, mais que focalizar conceitos específicos. Este trabalho 
possui poucas ideias pré-concebidas e salienta a importância das interpretações dos eventos mais do que a interpretação dos pesquisadores, além da coleta de dados sem instrumentos formais e estruturados, pode se dizer que não tentamos controlar o contexto da pesquisa, e sim, captar o contexto na totalidade. A pesquisa qualitativa, de acordo com Martins \& Ramos (2013),

Busca questões muito específicas e pormenorizadas, preocupando-se com um nível da realidade que não pode ser mensurado e quantificado. Acrescenta também o autor que ela age com base em significados, razões, desejos, crenças, valores, atitudes e outras características subjetivas próprias do ser humano que não podem ser limitadas a variáveis numéricas (Martins \& Ramos, 2013, p. 10 apud Teixeira, 2015, p. 12).

A pesquisa qualitativa, é um método de estudo investigado em pesquisas como as de Estrela (2018), Ludke \&Andrade (2013) e Koche (2011). Suassuna (2008, p. 349) afirma que na pesquisa qualitativa "o pesquisador coloca interrogações que vão sendo discutidas durante o próprio curso da investigação. Ele formula e reformula hipóteses, tentando compreender as mediações e correlações entre os múltiplos objetos de reflexão e análise".

O método de pesquisa utilizado para elaborar a Sequência Didática é qualitativo, pois o foco está no processo de construção da sequência, utilizando teorias de Transposição Didática para atingir o objetivo final; não há presença de gráficos, ou quantificação de dados, e o método de avaliação dessa SD não apresenta como objetivo analisar estatisticamente os dados e sim a teoria utilizada.

1) A pesquisa qualitativa, em geral, ocorre no ambiente natural com coleta direta de dados e o pesquisador é o principal instrumento;

2) Os dados coletados são preferencialmente descritivos;

3) A preocupação do processo é predominante em relação à do produto;

4) O "significado" que as pessoas dão as coisas e a sua vida são focos de atenção para o pesquisador e,

5) A análise de dados e informações tende a seguir um processo indutivo (Pereira, et. al., 2018, p. 67).

Polidoro \& Stignar (2010) afirmam que a Transposição Didática trata-se da transferência do saber científico (aquele dominado pelos cientistas) para o saber ensinado (aquele que ocorre nas salas de aula); os autores defendem ainda que essa transferência "não deve ser compreendida como a transposição do saber no sentido restrito do termo: apenas uma mudança de lugar. Supõe-se essa passagem como um processo de transformação do saber, que se torna outro em relação ao saber destinado a ensinar" (Polidoro \& Stignar, 2010, p. 2).

Considerando-se que um dos autores deste trabalho atua no setor de saneamento há aproximadamente oito anos, trabalhando como guia na ETE de Itajubá recebendo visitas de diversas instituições públicas e privadas de ensino da cidade, observando o comportamento do visitante e buscando as melhores técnicas para transpor o conhecimento, também podemos caracterizar este trabalho como pesquisa-ação, onde o pesquisador está inserido no contexto da pesquisa. Fonseca (2002) define a pesquisa-ação ao afirmar que ela,

[...] pressupõe uma participação planejada do pesquisador na situação problemática a ser investigada. O processo de pesquisa recorre a uma metodologia sistemática, no sentido de transformar as realidades observadas, a partir da sua compreensão, conhecimento e compromisso para a ação dos elementos envolvidos na pesquisa (Fonseca, 2002, p. 34).

Neste sentido, a experiência em visitas na ETE, os fatos de que a ETE Itajubá não apresentar sala de vídeo e nem um ambiente que permita a utilização de outros métodos pedagógicos foram utilizados como base para a pesquisa, pois deste modo, cada etapa do tratamento serviu como elemento da SD sobre a ótica da Transposição Didática.

\subsection{Etapas da Pesquisa}

Esta pesquisa, como citado anteriormente, leva em consideração experiências adquiridas durante o acompanhamento de visitas a ETE Itajubá, por meio das quais percebeu-se a necessidade de se elaborar uma sequência didática para facilitar a 
compreensão acerca dos processos de tratamento de esgoto, durante as visitas escolares, com base na teoria da transposição didática defendida por Chevallard (1991).

Inicialmente, por meio de pesquisas em escolas da cidade de Itajubá, foram identificados livros didáticos que fazem menção ao tratamento de esgoto; estes livros foram analisados com o objetivo de identificar como se constitui a linguagem utilizada para abordar os processos empregados no tratamento de esgoto, assim como os conteúdos químicos relacionados a estes processos. Após esta análise utilizou-se fotos da ETE Itajubá para elaboração da SD e posteriormente, elaborou-se um questionário para coleta de informações que podem trazer sugestões de aprimoramento para a mesma.

O saneamento está inserido na Base Nacional Comum Curricular (Brasil, 2018), como habilidade ligada a interpretação das condições de saúde. O procedimento adotado para analisar os conteúdos dos livros didáticos, foi identificar os conteúdos de Ciências e Química que apresentassem relação com os processos de tratamento de esgoto.

O primeiro livro analisado foi da disciplina de Ciências, do quinto ano do ensino fundamental, intitulado "Buriti mais interdisciplinar”, de autoria de Leporo et. al. (2017). Este livro é utilizado nas escolas Municipais de Itajubá e apresenta uma perspectiva interdisciplinar de Ciências, História e Geografia.

Desta forma, a obra busca segundo os autores, estabelecer as competências específicas de Ciências defendidas pela Base Nacional Comum Curricular que são:

1- Compreender as ciências como empreendimento humano, reconhecendo que o conhecimento científico é provisório, cultural e histórico.

2- Compreender conceitos fundamentais e estruturas explicativas das Ciências da natureza, bem como dominar processos, práticas e procedimentos da investigação cientifica, de modo a sentir segurança no debate de questões cientificas, tecnológicas e socioambientais e do mundo de trabalho.

3- Agir pessoal e coletivamente com respeito, autonomia, responsabilidade, flexibilidade, resiliência e determinação, recorrendo aos conhecimentos das Ciências da Natureza para tomar decisões frente a questões científico tecnológicas e socioambientais e a respeito da saúde individual e coletiva, com base em princípio éticos, democráticos, sustentáveis e solidários (Brasil, 2018).

Foi analisada então a unidade 4 da obra, que apresenta a temática disciplinar sobre lixo, água e tecnologia. Segundo os autores,

1- O objetivo do capítulo foi conhecer as primeiras iniciativas para construir um sistema de abastecimento de água no Brasil.

2- Reconhecer que o Saneamento básico é um direito dos cidadãos.

3- Conhecer os processos de tratamento de água e do esgoto e reconhecer sua importância.

4- Reconhecer a importância do descarte e da destinação correta do lixo para preservar o meio ambiente. 5 Relacionar consumo e geração de lixo (Leporo et. al., 2017, p. 140).

Inserido na unidade 4, analisou-se o tópico Tratamento de Esgoto, que é demonstrado aos alunos, principalmente através de ilustrações de uma ETE com leituras que acompanham as fases do mesmo.

Outro livro analisado, agora com o objetivo de identificar os conteúdos de Química que poderiam ser relacionados com os processos de tratamento de esgoto, foi o livro de Usberco e Salvador (2002) - Química, Volume Único. Este livro é dividido em Química Geral - parte 1, direcionado para o primeiro ano do ensino médio; Físico-Química - parte 2, direcionado ao segundo ano do ensino médio, e Química Orgânica - parte 3, direcionado ao terceiro ano do ensino médio.

Os conteúdos analisados nos livros didáticos, foram considerados então, na elaboração da SD e de acordo com a teoria defendida por Zabala (1998), representam uma das fontes de informação utilizadas para tal elaboração. Por último, foi elaborado um questionário que tem a finalidade de aperfeiçoar as visitas de acordo com o feedback dos visitantes, visto que a SD não é considerada como imutável, e sim, passível de melhorias e reconstrução caso necessário. 


\section{Resultados e Discussão}

\subsection{Seleção de conteúdos}

Após a análise do livro didático "Buriti mais interdisciplinar" do ensino fundamental, selecionou-se os conteúdos apresentados na Tabela 1 para compor a SD e serem relacionados ao tema tratamento de esgoto.

Tabela 1 - Conteúdos selecionados do livro "Buriti mais interdisciplinar".

\begin{tabular}{|c|c|}
\hline Conteúdo & Página \\
\hline Lixo, Água e Tecnologia & 140 \\
\hline Tratamento de esgoto & 140 \\
\hline
\end{tabular}

Fonte: Autores.

Na Tabela 1 é relevante se observar que por estarem na mesma página do livro, os conteúdos selecionados podem ser compreendidos como sequenciais, o que facilita a correção entre ambos. Os conteúdos selecionados no livro didático do ensino médio - Química Volume Único - com a mesma finalidade, são apresentados na Tabela 2.

Tabela 2 - Conteúdos selecionados do livro "Química - Volume Único”.

\begin{tabular}{|c|c|}
\hline Conteúdo & Página \\
\hline Matéria e Energia & 20 \\
\hline Unidade de Medida & 21 \\
\hline Substâncias e Misturas & 30 \\
\hline Processo de Separação de Misturas & 43 \\
\hline Equações Químicas & 51 \\
\hline Funções Inorgânicas & 217 \\
\hline Solubilidade e Curvas de Solubilidade & 271 \\
\hline Diluição de Soluções & 286 \\
\hline Mistura de Soluções & 287 \\
\hline Equilíbrio em meio aquoso & 414 \\
\hline Escala de pH & 419 \\
\hline Combustão & 475 \\
\hline
\end{tabular}

Fonte: Autores. 
Na Tabela 2 pode-se observar que para a discussão do tema, pode-se selecionar uma maior quantidade de conteúdos do que no livro do ensino fundamental, devido ao nível de ensino ser mais avançado. Em posse das tabelas supracitadas, deu-se início ao desenvolvimento da SD.

Vale ressaltar que normalmente as visitas à ETE Itajubá, se iniciam com a recepção dos visitantes, a qual é realizada no pátio externo do local; nesta etapa, os visitantes são orientados sobre todos os processos que serão acompanhados durante a visita, fazendo-se uma breve introdução sobre como o esgoto chega à estação a partir do momento que é gerado nas residências da cidade, processo que ocorre por meio da separação da água da chuva em que o esgoto é levado para as elevatórias (unidades compostas por grades idênticas as visualizadas durante a visita e por bombas que transportam o esgoto para a ETE).

\subsection{Sequência Didática}

Para a elaboração da SD, desenvolveu-se 7 momentos, sendo que cada momento corresponde a uma fase do tratamento de esgoto acompanhada durante as visitas; organizou-se então para cada etapa, os conteúdos teóricos que podem ser abordados e sugeriu-se ações a serem tomadas pelos profissionais técnicos para que a compreensão dos visitantes acerca dos processos, seja efetiva. Os dados supracitados estão dispostos na Tabela 3, de uma forma geral; contudo, eles são discutidos posteriormente com maiores detalhes.

Tabela 3 - Sequência Didática proposta para as visitas na ETE.

\begin{tabular}{|c|c|c|}
\hline Etapas & $\begin{array}{l}\text { Conceitos } \\
\text { Abordados }\end{array}$ & Ações \\
\hline Início da visita & $\begin{array}{l}\text { Separação de } \\
\text { Misturas, soluções } \\
\text { heterogêneas, lixo. }\end{array}$ & $\begin{array}{l}\text { Como esta etapa dá início a visita, pode-se realizar analogias que remetam aos conteúdos que serão } \\
\text { previamente abordados; como por exemplo a filtragem do café preparado em casa e a visualização de } \\
\text { duas fases em uma mistura de areia e água. Também é importante ressaltar a importância do } \\
\text { tratamento de esgoto, de uma perspectiva ambiental e social e discutir sobre o lixo presente na mistura. }\end{array}$ \\
\hline $\begin{array}{l}\text { Remoção de } \\
\text { areia }\end{array}$ & Densidade. & $\begin{array}{l}\text { Nesta etapa, deve-se explicar aos estudantes brevemente o conceito de densidade e sua relação com a } \\
\text { massa e o volume da matéria; aqui deve-se ressaltar que a areia é mais densa que a água por possuir } \\
\text { maior massa em relação ao volume e por esta razão, deposita-se ao fundo de um recipiente. }\end{array}$ \\
\hline $\begin{array}{l}\text { Medidor de } \\
\quad \text { vazão }\end{array}$ & $\begin{array}{l}\text { Volume e } \\
\text { medições, } \\
\text { tecnologia. }\end{array}$ & $\begin{array}{l}\text { Aqui a vazão é medida através de sensores na entrada da ETE; sendo assim, pode-se abordar } \\
\text { brevemente o conceito de volume, assim como as unidades de medida correspondentes (ml, L). } \\
\text { Também é importante ressaltar a relevância de se realizar medições precisas para que não haja erros no } \\
\text { processo; neste contexto cabe utilizar uma analogia do preparo de um bolo, onde a medição incorreta } \\
\text { do volume de leite adicionado interfere no resultado esperado. }\end{array}$ \\
\hline $\begin{array}{l}\text { Caixa de carvão } \\
\text { ativado }\end{array}$ & Absorção, adsorção & $\begin{array}{l}\text { Nesta etapa, primeiro deve-se questionar os alunos acerca da função do carvão, posteriormente pode-se } \\
\text { explicar aos visitantes que o carvão ativado utilizado é poroso e por isso adsorve os gases gerados da } \\
\text { ETE; é interessante abordar brevemente a diferença entre os conceitos de adsorção e absorção para não } \\
\text { gerar confusão de significados. }\end{array}$ \\
\hline $\begin{array}{l}\text { Reator } \\
\text { Anaeróbico } \\
\text { UASB }\end{array}$ & $\begin{array}{c}\text { Reação de } \\
\text { oxirredução }\end{array}$ & $\begin{array}{l}\text { Aqui, começa-se a tratar de reações químicas, e é de extrema relevância tratar com os alunos, mesmo } \\
\text { que brevemente, sobre o conceito de reação química por oxirredução e citar quais os elementos } \\
\text { presentes nesta fase que concernem esta característica à fase em questão. As reações podem ser escritas } \\
\text { no chão do local fazendo-se uso de giz para lousa, e para facilitar a compreensão dos alunos pode-se } \\
\text { mostrar uma maquete previamente confeccionada, ou então a imagem da mesma. }\end{array}$ \\
\hline $\begin{array}{l}\text { Queimador de } \\
\text { gases }\end{array}$ & $\begin{array}{l}\text { Combustão e } \\
\text { Solubilidade }\end{array}$ & $\begin{array}{l}\text { Na penúltima etapa, pode-se relacionar a queima dos gases com os processos de combustão. Aqui é } \\
\text { interessante tratar sobre o processo de combustão dos gases e fazer uma analogia que relacione a água } \\
\text { do mar e os diversos sais presentes na mesma, com a solubilização dos gases gerados no processo de } \\
\text { tratamento de esgoto. }\end{array}$ \\
\hline $\begin{array}{l}\text { Leito de } \\
\text { secagem do lodo }\end{array}$ & $\begin{array}{l}\text { Separação de } \\
\text { misturas }\end{array}$ & $\begin{array}{l}\text { Na última etapa é interessante relembrar os alunos dos conceitos de mistura e substância, assim como } \\
\text { explicar que a separação da água do lodo, ocorre pela evaporação da primeira. }\end{array}$ \\
\hline
\end{tabular}

Fonte: Autores. 
Por meio da Tabela 3, pode-se então visualizar as ações a serem tomadas para colocar a SD em prática, de acordo com cada etapa do tratamento e os conteúdos que podem ser abordados em cada uma delas. A primeira etapa tratamento, é composta por grades de $6 \mathrm{~mm}$ e $12 \mathrm{~mm}$, então comumente os alunos são recepcionados no pátio da ETE e direcionados para essas unidades, onde ficam do lado de fora do guarda corpo, sendo possível visualizar apenas o gradeamento; nesta etapa são citados pelos profissionais técnicos os materiais que chegam a ETE (plásticos, fios de cabelo, guimba de cigarro, brinquedos, chupetas entre outros) e também os mecanismos físicos utilizados para a separação destes materiais. A Figura 1 mostra o processo supracitado.

Figura 1 - Primeira Etapa do tratamento de esgoto: Gradeamento.

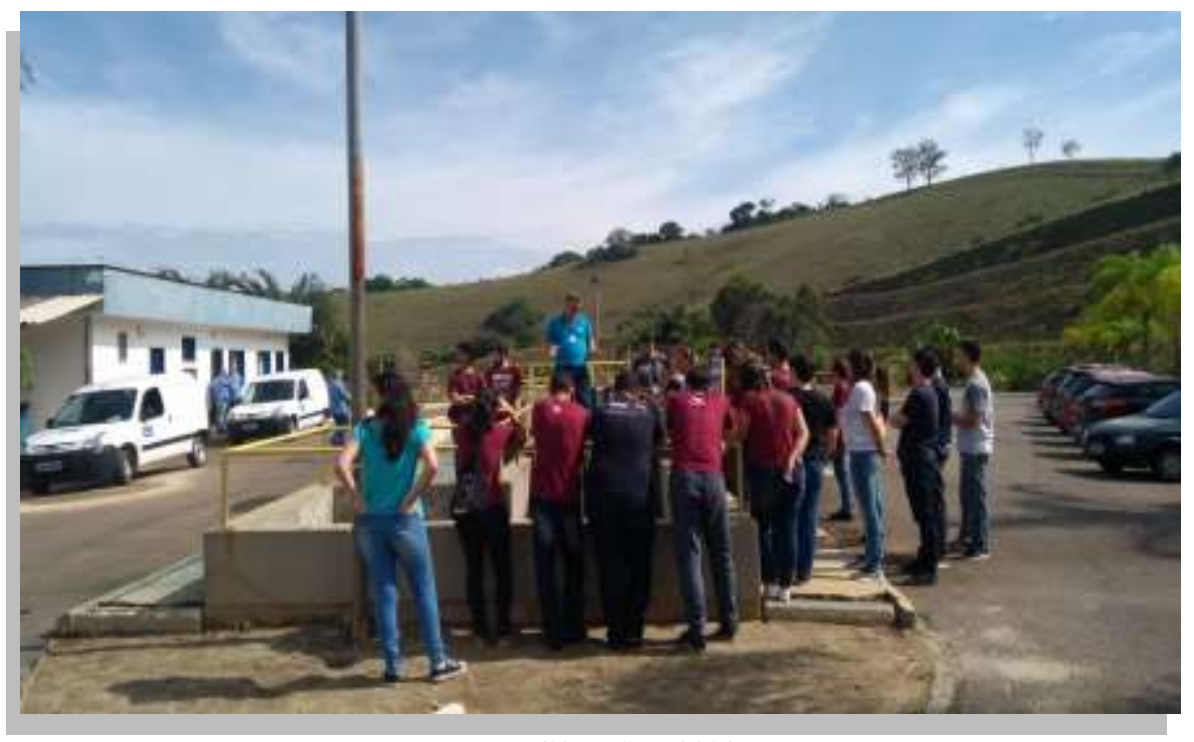

Fonte: COPASA (2020).

Na Figura 1 é relevante se observar que os visitantes têm contato direto com a etapa de gradeamento, sendo assim, podem visualizar a etapa com riqueza de detalhes. Na Figura 2, estão representados os processos que podem ser relacionados aos conteúdos sobre sepraração de misturas, densidade e lixo.

Figura 2 - Etapas de gradeamento: Respectivamente, grades de 6mm (A); material Separado (B); grades de 12 mm e desarenador $(\mathrm{C})$.
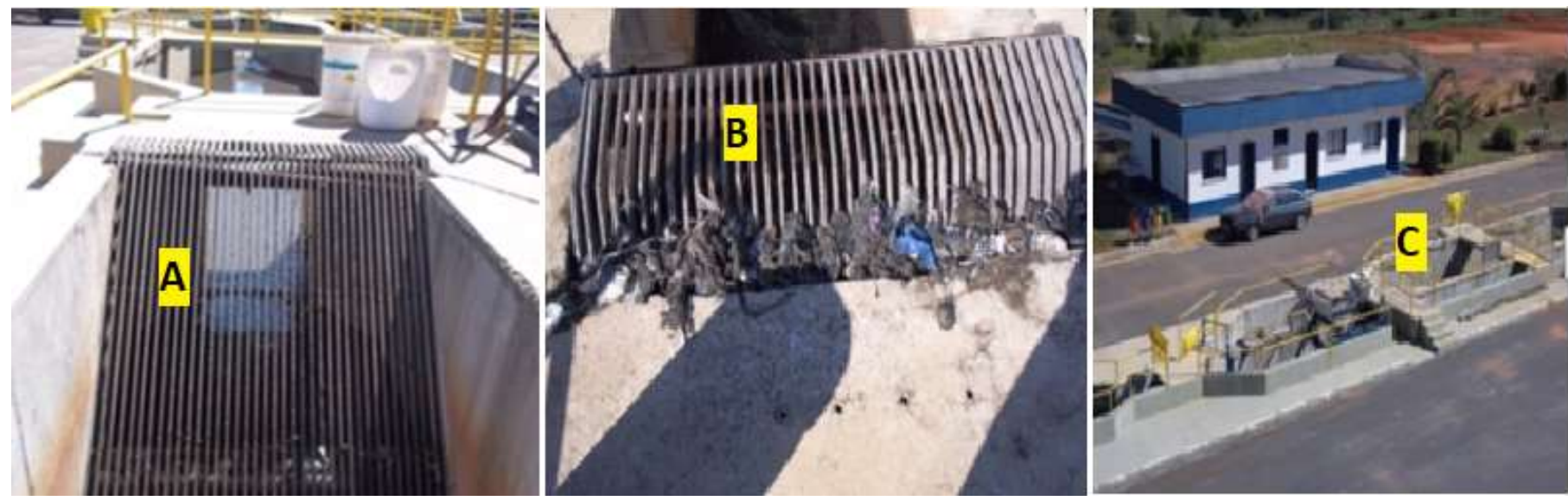

Fonte: COPASA (2015) - Adaptado. 
Nos momentos representados pelas Figuras 2A e 2B pode-se então utilizar o conceito de separação de misturas e os conceitos relativos ao lixo, pois tratam-se de conteúdos apresentados no quinto ano do ensino fundamental e no primeiro ano do ensino médio, e a estratégia de ensino sugerida para ser utilizada é a contextualização. Já no momento representado pela Figura 2C onde está presente o desarenador, pode-se fazer uma relação com o conteúdo de densidade, onde a areia por possuir mais massa é decantada para o fundo do recipiente e posteriormente encaminhada para os leitos de secagem; o conteúdo de densidade por sua vez, é comumente abordado no nono ano do ensino fundamental e no segundo ano do ensino médio.

A característica da Transposição didática defendida por Chevallard (1991 apud Tognasca Júnior, 2017) que corrobora com a sugestão apresentada na SD para estes dois momentos, é a adaptação da linguagem, visto que para explicar aos visitantes o processo de separação na etapa de gradeamento, são sugeridas analogias (como por exemplo a da filtragem do café, que pode ser diretamente relacionada com o processo visualizado na Figura 2B), as quais os alunos podem fazer uma associação com o processo visualizado e desta forma obter uma maior compreensão.

A próxima etapa, consiste na medição de vazão, em que os visitantes passam pela Calha Parshall, onde há uma régua com a qual se faz a medição manual da vazão; aqui é comentado que essa medição tem o objetivo de ser comparada com o medidor ultrassônico, que é um sensor que faz a leitura da vazão de esgoto que entra na ETE e fica junto com a calha; essa comparação é realizada pois os sensores podem vir a apresentar falhas, e esta etapa é de extrema importância pois a vazão que entra na estação está diretamente ligada a eficiência do tratamento.

A estratégia didática utilizada nesta etapa é a comparação com as medidas volumétricas estudadas dentro do conteúdo de densidade referido no momento anterior da SD, desta forma os alunos podem perceber a importância dos conceitos de volume, e reconhecem na prática, como a química está presente nas tarefas dos diversos setores da sociedade, entre eles o saneamento básico. A característica de TD neste caso, é a adaptação de linguagem e a interpretação do aluno, levando em consideração o aprendizado que esse aluno traz consigo, o que também se dá como uma característica da TD.

Ainda na etapa correspondente a Calha Parshall, é indicado aos alunos que a leitura de vazão também pode ser realizada por leitor magnético, e caso haja um erro no sistema eletrônico, o sistema manual realiza a medição. Aqui pode-se apontar que as estratégias didáticas utilizadas são a contextualização, a adaptação da linguagem e a simplificação do conteúdo, características da TD defendidas por Astolfi (1995 apud Brockington e Pietrocolo, 2005); pois é informado ao aluno, por meio da analogia do preparo do bolo, a importância de se realizar medidas corretas de vazão, pois a eficiência do tratamento depende diretamente desta etapa.

A Calha Parshall é representada na Figura 3 (A), assim como a caixa de carvão ativado 3 (B), que consiste na próxima etapa do tratamento de esgoto e tem o objetivo de adsorver os gases gerados pela turbulência do esgoto. 
Figura 3- Calha Parshall (A) e Caixa de carvão ativado (B).

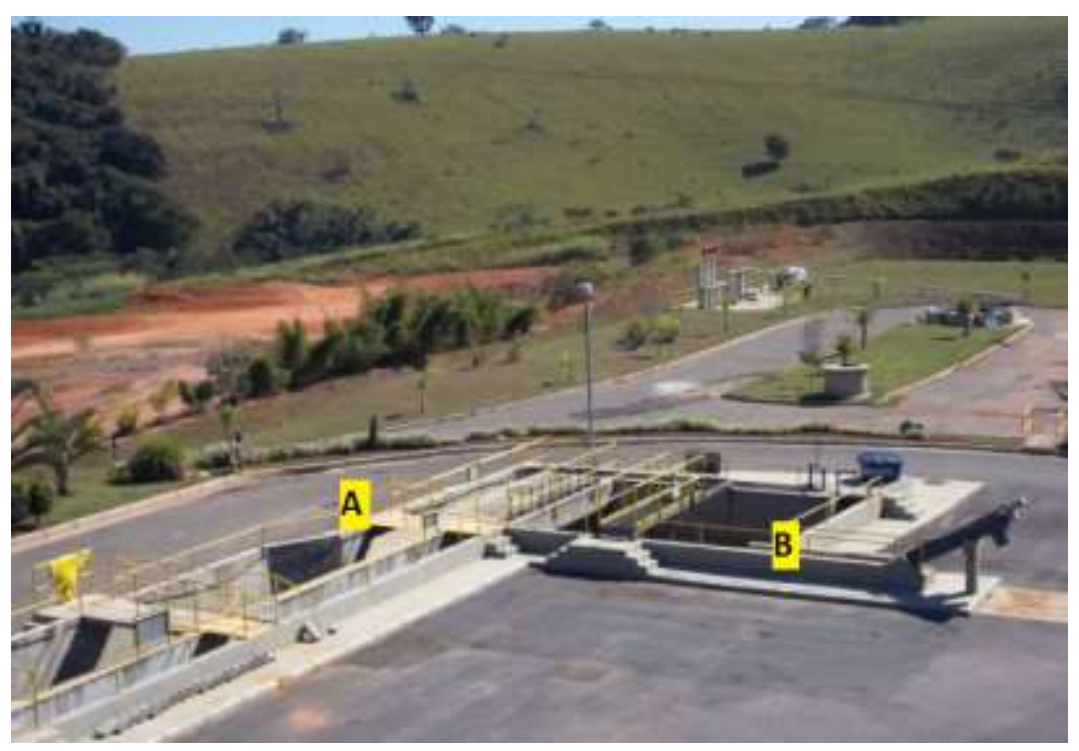

Fonte: COPASA (2015) - Adaptado.

Na etapa representada pela Figura 3 (B), deve-se fazer o questionamento apresentado anteriormente (sobre a função do carvão ativado) e depois, realizar uma complementação das respostas obtidas, explicando então aos alunos a função do carvão ativado de adsorver os gases e que isso ocorre devido ao fato de que ele apresenta uma área superficial grande e devido às propriedades de seus poros; é interessante apontar que este material é utilizado em filtros para tratamento de água e nas residências, nos filtros domésticos. A estratégia didática e a característica de TD defendida por Chevallard (1991 apud Tognasca Júnior, 2017) utilizadas neste caso, é a contextualização; nessa etapa utiliza-se o conceito de adsorção, que por sua vez, é um conceito inserido no estudo de Físico-Química do segundo ano do ensino médio.

A próxima etapa, consiste na passagem pelas coroas de distribuição de vazão, pelo reator UASB; onde os alunos podem visualizar como o esgoto é distribuído no reator anaeróbico. Aqui é comentado com os alunos que nos reatores acontece a oxirredução da matéria orgânica formando-se sulfetos, nitrogênio e metano. Vale ressaltar aqui que o metano é gerado a partir da redução de compostos como por exemplo o dióxido de carbono. Neste caso, a estratégia utilizada é a pintura no chão das reações que ocorrem no processo, conforme a Figura 4. 
Figura 4 - Reações redox que ocorrem no reator UASB durante o tratamento de esgoto.

Tabela 5 - Algumas reações de redox importantes na digestão anaeróbia

\begin{tabular}{|c|c|c|}
\hline Processo & Reação de Oxidação & $\begin{array}{c}\Delta \mathbf{G}_{0} \\
(\mathrm{KJ} / \mathrm{mol})\end{array}$ \\
\hline $\begin{array}{l}\text { Propionato } \\
\text { a acetato }\end{array}$ & $\mathrm{CH}_{3} \mathrm{CH}_{2} \mathrm{COO}^{-}+3 \mathrm{H}_{2} \mathrm{O} \rightarrow \mathrm{CH}_{3} \mathrm{COO}^{-}+\mathrm{H}^{+}+\mathrm{HCO}^{3-}+3 \mathrm{H}_{2}$ & $+76,1$ \\
\hline $\begin{array}{l}\text { Butirato a } \\
\text { acetato }\end{array}$ & $\mathrm{CH}_{3} \mathrm{CH}_{2} \mathrm{CH}_{2} \mathrm{COO}^{-}+2 \mathrm{H}_{2} \mathrm{O} \rightarrow 2 \mathrm{CH}_{3} \mathrm{COO}^{-}+\mathrm{H}^{+}+2 \mathrm{H}_{2}$ & $+48,1$ \\
\hline $\begin{array}{l}\text { Etanol a } \\
\text { acetato }\end{array}$ & $\mathrm{CH}_{3} \mathrm{CH}_{2} \mathrm{OH}^{+}+\mathrm{H}_{2} \mathrm{O} \rightarrow \mathrm{CH}_{3} \mathrm{COO}^{-}+\mathrm{H}^{+}+2 \mathrm{H}_{2}$ & $+9,6$ \\
\hline $\begin{array}{l}\text { Lactato a } \\
\text { acetato }\end{array}$ & $\mathrm{CH} 3 \mathrm{CHOHOO}^{-}+2 \mathrm{H}_{2} \mathrm{O} \rightarrow \mathrm{CH}_{3} \mathrm{COO}^{-}+\mathrm{H}^{+}+\mathrm{HCO}^{--}+2 \mathrm{H}_{2}$ & $-4,2$ \\
\hline \multicolumn{3}{|c|}{ Reação de Redução } \\
\hline $\begin{array}{l}\text { Bicarbonato } \\
\text { a acetato }\end{array}$ & $2 \mathrm{HCO}_{3}^{-}+4 \mathrm{H}_{2}+\mathrm{H}+\rightarrow \mathrm{CH}_{3} \mathrm{COO}^{-}+4 \mathrm{H}_{2} \mathrm{O}$ & $-104,6$ \\
\hline $\begin{array}{l}\text { Bicarbonato } \\
\text { a metano }\end{array}$ & $\mathrm{HCO}_{3}^{-}+4 \mathrm{H}_{2}+\mathrm{H}+\rightarrow \mathrm{CH}_{4}+3 \mathrm{H}_{2} \mathrm{O}$ & $-135,6$ \\
\hline $\begin{array}{l}\text { Sulfato a } \\
\text { sulfeto }\end{array}$ & $\mathrm{SO}_{4}^{2-}+4 \mathrm{H}_{2}+\mathrm{H}+\rightarrow \mathrm{HS}^{-}+4 \mathrm{H}_{2} \mathrm{O}$ & $-151,9$ \\
\hline
\end{tabular}

Fonte: Chernicharo, 1997 apud Hamerski (2012).

Na Figura 4 é interessante observar que estão descritas reações de oxidação e redução, o que abre oportunidade para trabalhar o tema de maneira bastante completa. A característica de TD neste caso, é a adaptação da linguagem e associação do conteúdo com os processos ocorridos no reator; ainda de acordo com a teoria defendida por Chevallard (1991 apud Tognasca Júnior, 2017), podemos identificar nesta etapa que o saber escolar é transformado em saber ensinar, presente nas equações químicas. Aqui, para facilitar o entendimento dos alunos, quanto a entrada de esgoto no reator, e a separação que ocorre dentro do reator, pode-se confeccionar uma maquete conforme modelo da Figura 5, ou apenas mostrar a imagem da mesma.

Figura 5 - Maquete de um reator anaeróbico de fluxo ascendente.

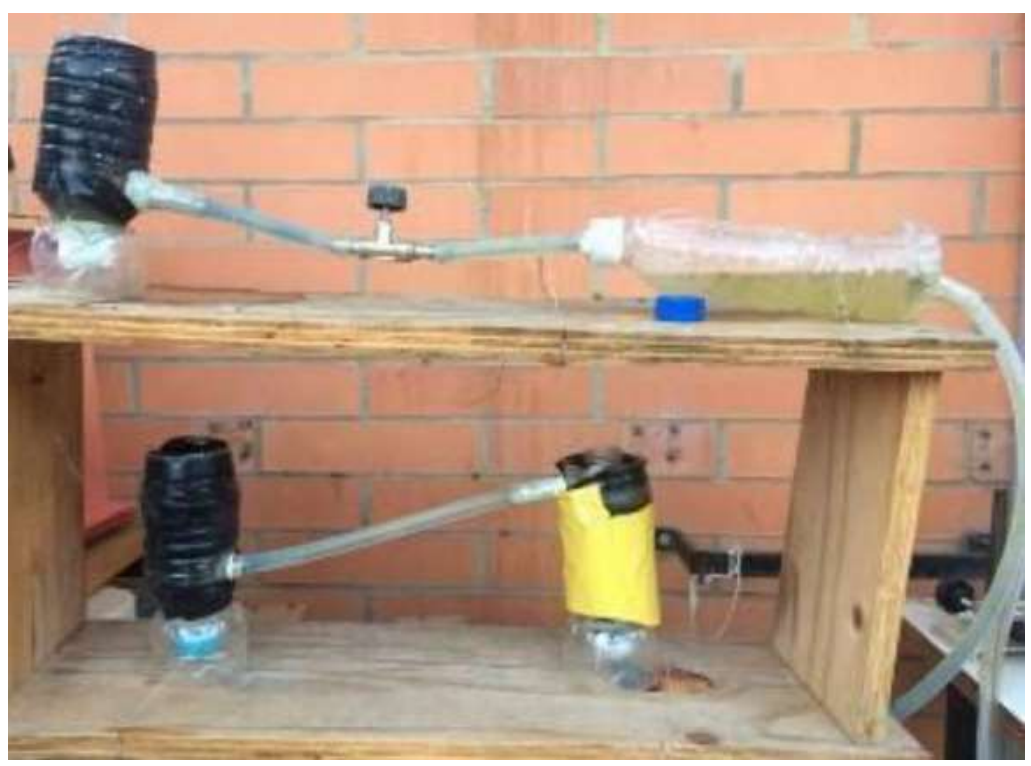

Fonte: Cirino, et al., (2019). 
A maquete representada na Figura 5 tem como objetivo de estratégia didática facilitar a visualização do aluno e complementar a fala do profissional técnico que por meio dela pode explicar que dentro do reator ocorre a separação de líquido (efluente tratado), é gerado gás que vai para o queimador, e é produzido lodo que por sua vez, será direcionado para o leito de secagem; a maquete proporciona estas explicações pois representa o interior do reator anaeróbico que não pode ser visualizado na visita à ETE, sendo assim, a característica de TD identificada neste caso é a adaptação dos processos, pela qual Chevallard (1991 apud Tognasca Júnior, 2017) defende que o saber ensinar passa por adaptações para chegar ao saber ensinado.

Agora tratando-se da queima dos gases, é explicado aos visitantes que os gases gerados no processo, são direcionados para as estruturas denominadas 'coifas' e posteriormente são transportados por tubos de policloreto de vinila - PVC (Figura 6A). Após este transporte, os gases passam por uma caixa denominada 'selo hídrico' cujo objetivo é evitar explosão do sistema caso haja regresso no trajeto, pois a mesma, contém água capaz de solubilizar estes gases, especialmente o sulfeto de hidrogênio $\left(\mathrm{H}_{2} \mathrm{~S}\right)$ que é produzido nos reatores através da redução de sulfato e sulfito (Figuras 6B e 6C). Nesta etapa a estratégia didática é a pintura das reações, assim como na etapa em que são tratadas as reações de oxirredução. As reações envolvidas na redução de sulfato são apresentadas a seguir, por meio das Equações 1 e 2 (Widdel \& Hansen apud van Lier et al., 2008).

$$
\begin{aligned}
& \text { (Equação 1) } \mathrm{H}_{2(\mathrm{~g})}+0,25 \mathrm{SO}_{4}{ }^{2-}{ }_{(\mathrm{aq})}+0,25 \mathrm{H}^{+} \rightarrow 0,25 \mathrm{HS}^{-}+\mathrm{H}_{\mathrm{O}} \mathrm{O}_{(\mathrm{l})} \\
& \text { (Equação 2) } \quad \mathrm{CH}_{3} \mathrm{COO}_{(\mathrm{aq})}^{-}+\mathrm{SO}_{4}{ }^{2-}{ }_{(\mathrm{aq})}+\mathrm{H}_{2} \mathrm{O}_{(\mathrm{l})} \rightarrow \mathrm{HS}^{-}+2 \mathrm{HCO}_{3 \text { (aq) }}
\end{aligned}
$$

Reações de redução e solubilidade são conteúdos ministrados no segundo ano do ensino médio na vertente de Físico Química, no caso do segundo, este será trabalhado através da analogia da água do oceano, que é uma solução na qual diversos sais estão dissolvidos; serão citados como exemplo cloreto de sódio $(\mathrm{NaCl})$, cloreto de magnésio $\left(\mathrm{MgCl}_{2}\right)$ e sulfato de magnésio $\left(\mathrm{MgSO}_{4}\right)$. A estratégia didática utilizada neste caso, trata-se da adaptação da linguagem e contextualização do conteúdo, com o contexto da visita, além disso, está inserida nesta nessa etapa a questão do saber ensinar transformado em saber ensinado, como defende a teoria de Chevallard (1991 apud Tognasca Júnior, 2017).

É interessante ressaltar que nesta etapa o aluno pode ser instigado a pensar em como aproveitar o gás gerado no tratamento; aqui cabe o questionamento de se a combustão dos gases gerados no tratamento, principalmente o metano, pode gerar energia, e se essa energia pode ser aproveitada. Esta etapa de transporte, solubilização e queima dos gases está representada na Figura 6. 
Figura 6 - Etapas da queima dos gases produzidos no tratamento de esgoto. Respectivamente, coifa do Reator UASB (A); linha de distribuição de gás produzido no Reator UASB (B); selo hídrico (Caixa com água para evitar explosão) (C).
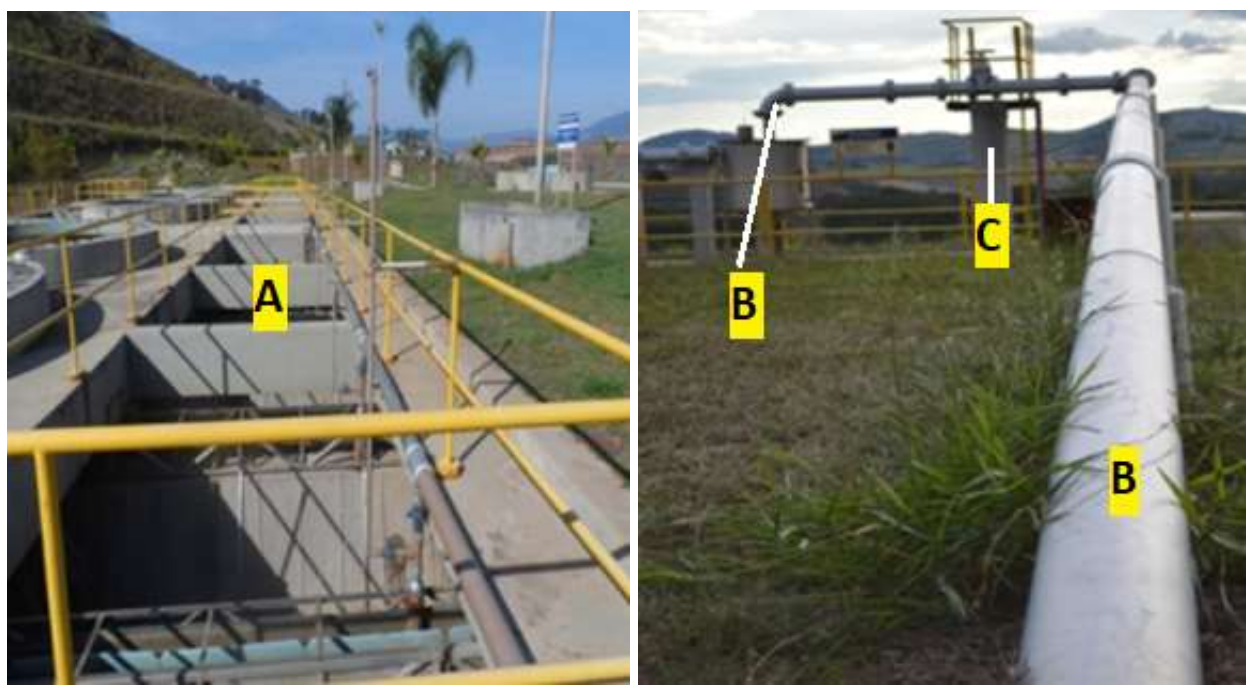

Fonte: COPASA (2015) - Adaptado.

Na Figura 6 é relevante se observar que as etapas de queima de gases são sequênciais e que portanto, todas devem ocorrer de maneira precisa para que não ocorram erros no processo e possíveis acidentes, como por exemplo o vazamento destes gases para a atmosfera.

A sétima e última etapa, consiste no leito de secagem do lodo. Aqui é ensinado aos visitantes que o lodo proveniente do reator, é direcionado para essas unidades, em que o processo de evaporação desidrata o lodo que posteriormente é acondicionado no aterro na própria ETE. A estratégia didática utilizada é a contextualização pois será explicitado que neste momento ocorre o processo de evaporação natural, como na secagem de roupas no varal, por exemplo; sendo assim pode-se afirmar que a característica de TD é a adaptação da linguagem e contextualização. Evaporação é um conteúdo estudado no nono ano do ensino fundamental na disciplina de ciências, e no primeiro ano do ensino médio na disciplina de química.

A Tabela 4 apresenta resumidamente as características de TD apresentadas para a pedagogização da visita na ETE Itajubá, de acordo com as etapas sugeridas na SD.

Tabela 4 - Resumo de características de TD presentes na SD proposta neste trabalho.

\begin{tabular}{|c|c|}
\hline \multicolumn{1}{|c|}{ ETAPA } & CARACTER ÍSTICA DE TD \\
\hline Gradeamento & Transferência do saber \\
\hline Decantação da areia & Saber ensinado. \\
\hline Medidor de vazão & Adaptação da linguagem. \\
\hline Caixa de carvão & Transferência do saber, transformar um saber em exercícios e \\
\hline Reator & problemas. \\
\hline Queimador de gás & Saber escolar transformado em saber ensinar. Adaptação do saber \\
\hline Leito de secagem & Transformar um saber em exercícios e problemas. \\
\hline
\end{tabular}

Fonte: Autores. 
Ao analisarmos a Tabela 4, pode-se identificar a contextualização e adaptação do saber como características marcantes de TD, assim como transferência do saber. Por meio disto, pode-se estabelecer uma efetivação da transposição interna, em que o saber ensinar se transforma em saber ensinado, visto que este é um dos objetivos da técnica de TD, por meio da qual o aluno pode compreender de forma mais didática e mais efetiva todos os processos relacionados ao tratamento de esgoto.

Após passarem por todas as etapas do tratamento de esgoto será disponibilizada uma prancheta e uma caneta para que todos os visitantes preencham o questionário conforme detalhado na Tabela 5, para coletar dados e conhecer o perfil dos visitantes e a partir destes dados, revisar continuamente a sequência didática apresentada na visita.

Tabela 5 - Questionário proposto ao visitante para avaliar a visita.

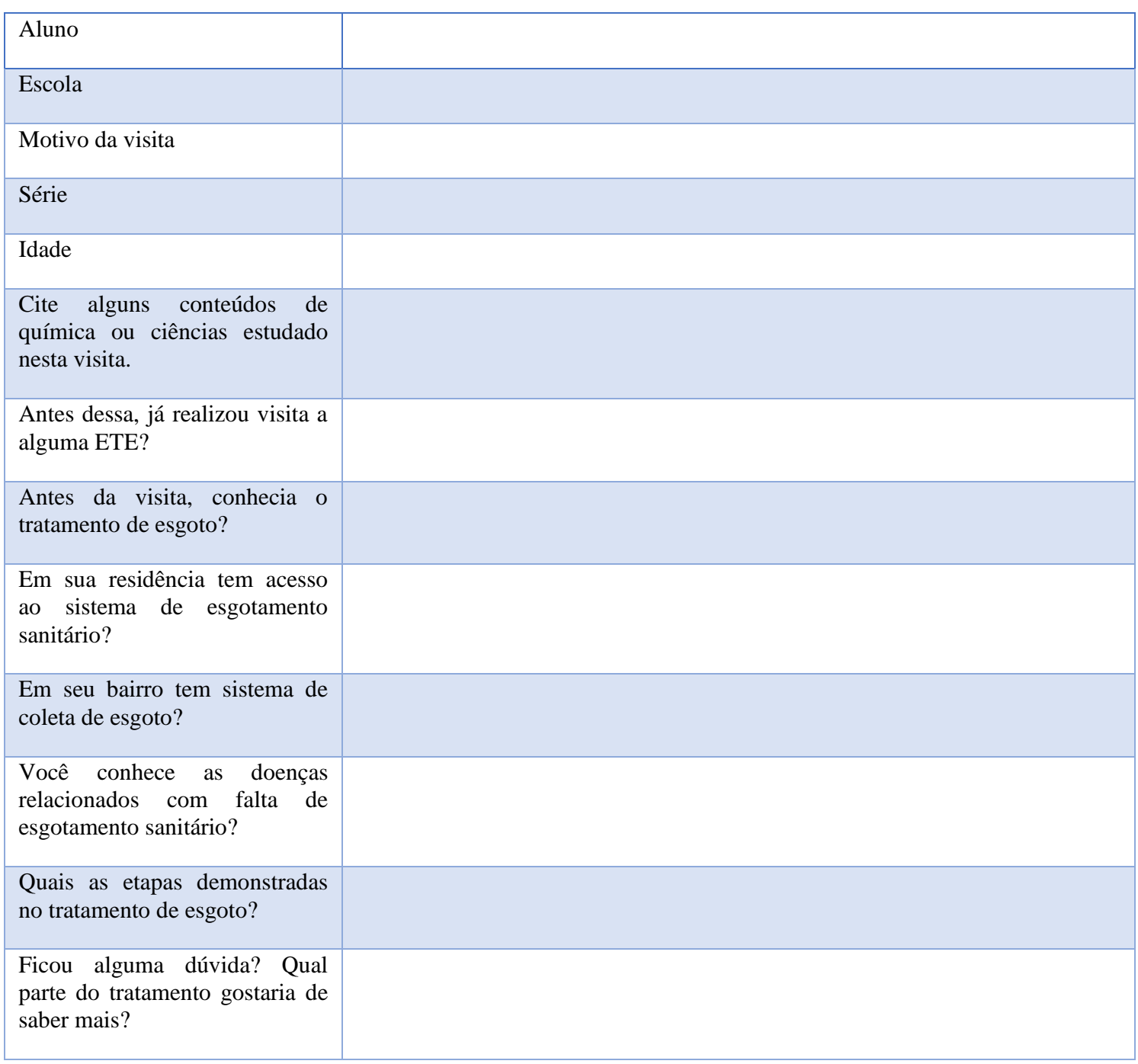

Fonte: Autores.

Com base nas respostas do questionário exposto na Tabela 5 sobretudo na última pergunta, que se refere a possíveis dúvidas, adaptações poderão ser feitas na SD para aprimorar o processo de ensino-aprendizagem neste ambiente não-formal.

\section{Considerações Finais}

O tratamento de esgoto é uma atividade importante para a saúde e o bem estar da população, além de preservar os recursos hídricos. 
Como a visita a ETE é uma atividade que se pode ser apresentada com um objeto de estudo para o ensino, o presente trabalho propôs aprimorar as visitas a ETE Itajubá, através da proposição de uma sequência didática relacionada aos processos de tratamento de esgoto. Para realizar esse estudo foi utilizado como teoria a Transposição Didática.

Este estudo buscou articular os conteúdos científicos, os quais apresentam relação com o tratamento de esgoto; para isso, usou-se de livros didáticos utilizados nas escolas públicas de Itajubá, que por sua vez, foram uma ferramenta de busca para que esta relação fosse possível e pautada em um referencial teórico confiável.

A elaboração da SD foi feita utilizando os seguintes itens, apresentação de uma situação problema que faça parte do cotidiano dos alunos, verificação do conhecimento prévio dos alunos e fontes de informação através da análise dos conteúdos dos livros didáticos. Para melhorar a visita e aprimorar a experiência, um questionário será utilizado, para coletar informações e identificar o perfil dos visitantes a fim adaptar a Sequência Didática com o perfil dos visitantes.

Espera-se que este trabalho contribua para orientar os técnicos que recebem as visitas às ETE, e assim, possa contribuir para auxiliar o estudante na compreensão das ciências e no que tange a educação ambiental, principalmente na conscientização da importância de não descartar materiais não biodegradáveis na rede de esgoto e nos rios.

Para trabalhos futuros, sugere-se o desenvolvimento de ações relacionadas aos temas de tratamento de água e tratamento de esgoto, que tenham por objetivo proporcionar um maior aproveitamento para o processo de ensino e aprendizagem e inserir no contexto escolar uma discussão mais profunda sobre a relação entre a ciência, a tecnologia e a sociedade; para que desta forma os alunos da educação básica construam uma sólida formação, desenvolvendo suas capacidades cognitivas, políticas e sociais para atuar como um cidadão ativo na sociedade. Sugere-se ainda, maior interação da escola com os órgãos responsáveis por tais processos, para fins de diálogo e desenvolvimento de ações conjuntas, como a descrita neste trabalho.

\section{Referências}

Astolfi, J-P e Develay, M. (1995). A Didática das Ciências. Papirus.

Brasil. Ministério da Educação. Base Nacional Comum $\quad$ Curricular. $\quad$ Brasília, 2018. http://basenacionalcomum.mec.gov.br/images/BNCC_EI_EF_110518_versaofinal_site.pdf.

Brockington, Guilherme; Pietrocola, Maurício. (2005). Serão as regras da transposição didática aplicáveis aos conceitos de física moderna? In: Investigações em Ensino de Ciências. v. 10 n. 3, p. 387-404. https://www.if.ufrgs.br/cref/ojs/index.php/ienci/article/view/512.

Cirino, M. M. M.; Rocha, L. M.; Da Silva, M. R. A. (2019). Tratamento de Efluentes aplicando combinações de processos convencionais e processos oxidativos avançados. Revista Augustus, v. 24, n. 49, p. 24-37.

Chevallard, Y. (1991). La transposición didáctica: del saber sabio al saber enseñado. Buenos Aires: Aique.

Copasa. Companhia de Saneamento de Minas Gerais. (2020). Programa Chuá - Educação Sanitária e Ambiental da Copasa - Saneamento, coleta e tratamento de esgoto. Belo Horizonte, MG. http://www.copasa.com.br/wps/portal/internet/pesquisa-escolar/destaques/historico-programa-chua. .

Costa, J. A.; Araújo, F. C.; Seixas, M. S.; Chagas, M. S.; Góes, M. J. (2019). A contribuição das visitas técnicas para o ensino de biologia nas escolas de ensino médio. In: VI Congresso Nacional de Educação. 24 a 26 de 2019 . Fortaleza - CE. https://www.editorarealize.com.br/editora/anais/conedu/2019/TRABALHO_EV127_MD4_SA1_ID1777_14082019194613.pdf .

Costa, W. G. de C.; Silva, M. R. A. da; silva, L. C. da. (2021). "Treating water": A didactic game for teaching chemistry with a focus on the Science, Technology and Society - STC approach. Research, Society and Development, [S. l.], v. 10, n. 4, p. e35210414237, 2021. DOI: 10.33448/rsd-v10i4.14237. https://www.rsdjournal.org/index.php/rsd/article/view/14237

Estrela, C. (2018). Metodologia Científica: Ciência, Ensino, Pesquisa. Editora Artes Médicas.

Fonseca, J. J. S. (2002). Metodologia da Pesquisa Científica. Universidade Estadual do Ceará. Curso de Especialização em Comunidades Virtuais de Aprendizagem - Informática Educativa. Ceará.

Hamerski, Fernando. (2012). Partida de um reator anaeróbico de fluxo ascendente com manta de lodo (UASB) no tratamento de efluentes provenientes de uma indústria de laticínios. $76 \mathrm{f}$. Dissertação (pós-graduação) - Universidade Federal de Santa Maria, Santa Maria, RS. https://repositorio.ufsm.br/ bitstream/handle/1/7960/HAMERSKI\%2c\%20FERNANDO.pdf?sequence=1\&isAllowed=y.

Koche, J. C. (2011). Fundamentos de metodologia científica. Petrópolis: Vozes. http://www.brunovivas.com/wpcontent/uploads/sites/10/2018/07/K\%C3\%B6che-Jos\%C3\%A9-Carlos0D0AFundamentos-de-metodologia-cient\%C3\%ADfica-_teoria- 
da0D0Aci\%C3\%AAncia-e-inicia\%C3\%A7\%C3\%A3o-\%C3\%A0

pesquisa.pdfhttps://repositorio.ufsm.br/bitstream/handle/1/15824/Lic_Computacao_Metodologia-Pesquisa-Cientifica.pdf?sequence=1 .

Leporo, N.; CruvineI, M. T.; Righi, F. P. (2017). Buriti Mais Interdisciplinar-Ciências, História e Geografia. $1^{\text {a }}$ ed. Editora Moderna. São Paulo.

Lopes, A. C. F.; Leandro, E. F.; Bomfim, A. C.; Dias, A. L. (2015). A educação não formal: Um espaço alternativo da educação. XII Congresso Nacional de Educação - Anais. 26 a 29 de outubro. Curitiba - PR. https://educere.bruc.com.br/arquivo/pdf2017/25198_12669.pdf .

Ludke, M. \& Andre, M. E . D. A. (2013). Pesquisas em educação: uma abordagem qualitativa. São Paulo: E.P.U.

Martins, Ronei Ximenes; Ramos, Rosana. (2013). Metodologia de pesquisa: guia de estudos. Lavras: UFLA, p. 8-21.

Oliveira, Emanuel Romário. (2018). Uma proposta de sequência didática em website para o ensino de transferência de calor. 2018-a. 69 f. Dissertação (Mestrado em Ensino de Física) - Universidade Tecnológica Federal do Paraná, Medianeira. https://repositorio.utfpr.edu.br/jspui/handle/1/3961.

Pereira A. S. et al. (2018). Metodologia da pesquisa científica. [free e-book]. Santa Maria/RS. Ed. UAB/NTE/UFSM.

Polidoro, L. F.; Stignar, R. (2010). A transposição didática: A passagem do saber científico para o saber escolar. Revista de Tecnologia \& Cultura Ciberteologia. Ano VI, n. 27. http://www.educadores.diaadia.pr.gov.br/arquivos/File/2010/artigos_teses/2010/Ensino_religioso/transposicao_didatica.pdf .

Suassuna, L. (2008). Pesquisa Qualitativa em Educação e Linguagem: histórico e validação do paradigma indiciário. Rev. Perspectiva, v. 26, n. 1, 341-377, jan./jun. Florinópolis - SC. Disponível em: <https://periodicos.ufsc.br/index.php/perspectiva/article/download/2175-795x.2008v26n1p341/9576/30864 .

Teixeira, F. N. (2015). Metodologias de pesquisa em Educação: Possibilidades e adequações. Caderno Pedagógico, lajeado. V. 12, n. 2, p. 7-17. ISSN 19830882. http://www.univates.br/revistas/index.php/cadped/article/viewFile/955/943.

Tognasca Júnior, Rodolfo. (2017). A introdução do tema Saneamento no Curso de Medicina visando transposição didática para a Educação Básica. 2017. 2017. $124 \mathrm{f}$. Dissertação (Mestrado Profissional em Ensino de Ciências) - Universidade Federal de Itajubá, Itajubá,. https://repositorio.unifei.edu.br/xmlui/bitstream/handle/123456789/916/dissertacao_tognasca_junior_2017.pdf?sequence=1\&isAllowed=y .

van Lier, J. B.; Mahmoud, N.; Zeeman G. (2008). Anaerobic wastewater treatment. In: Henze, M.; van Loosdrecht, M. C. M.; Ekama, G. A. et al. (Ed.) Biological wastewater treatment, principles, modelling and design. Chapter 16. London: IWA Publishing. p. 415-456.

Zabala, A. (1998). Prática Educativa: como ensinar. Porto Alegre: ARTMED. 